\title{
Conflicting rates of increase in the sperm whale population of the eastern Caribbean: positive observed rates do not reflect a healthy population
}

\author{
Hal Whitehead ${ }^{1, *}$, Shane Gero ${ }^{1,2}$ \\ ${ }^{1}$ Department of Biology, Dalhousie University, 1355 Oxford St, Halifax B3H 4J1, Canada \\ ${ }^{2}$ Present address: Department of Bioscience, University of Aarhus, C.F. Møllers Allé 3, Building 1131, Room 228, \\ 8000 Aarhus C, Denmark
}

\begin{abstract}
Observed rates of increase calculated from trends in the numbers of animals present in a population should generally agree with those estimated from life-history data. However, for a small population of individually identified sperm whales Physeter macrocephalus occupying the waters of the eastern Caribbean there is a discrepancy. Using a mark-recapture analysis that included heterogeneity in identification, the population, numbering about 156 adults $(95 \%$ CI 126-195) in 1998, has been increasing at $3.4 \% \mathrm{yr}^{-1}\left(95 \%\right.$ CI: $\left.1.0-5.7 \% \mathrm{yr}^{-1}\right)$. However, a 2-stage matrix population model including unweaned calves and adults (and excluding mature males), whose parameters were estimated directly from empirical data, gave a projected rate of increase of $-2.7 \% \mathrm{yr}^{-1}$ (95\% CI: -5.4 to $-0.4 \% \mathrm{yr}^{-1}$ ). This estimate is primarily sensitive to calculated adult mortality. The discrepancy between the observed and projected rates of increase for this population may be explained by a high, probably anthropogenic, mortality of sperm whales in the eastern Caribbean, coupled with immigration from surrounding regions, so the area becomes an attractive sink (ecological trap). The analysis emphasizes the fragility of sperm whale populations. More generally, our analysis of this population shows that a positive observed rate of increase is not necessarily a sign of a healthy population. This case study highlights the importance of analysing populations of endangered species using multiple methodologies and with a solid base of individual-level empirical data based on longitudinal monitoring.
\end{abstract}

KEY WORDS: Population modelling $\cdot$ Rate of increase $\cdot$ Life history $\cdot$ Mark-recapture $\cdot$ Mortality $\cdot$ Sperm whale $\cdot$ Attractive sink $\cdot$ Ecological trap

\section{INTRODUCTION}

The rate of increase is a fundamental concept in population biology. As such, it has been incorporated into conservation biology, constituting a metric of the health of an at-risk population, as well as its potential for recovery (e.g. Pereira et al. 2004). In practice, there are 3 different notions of 'rate of increase' (Caughley \& Birch 1971) $)^{\mathbf{1}}$.

The 'observed rate of increase' $(r)$ is the per capita rate at which the population size is increasing or declining. This is usually estimated using census data or mark-recapture analyses of individual identifications (Fagan et al. 2010).

We will call the rate of increase predicted by schedules of survival and fecundity the 'projected rate of increase' $\left(r_{\mathrm{s}}\right)$. This was traditionally calculated from life table data, but nowadays often comes from

1Fagan et al. (2010), however, present a somewhat different classification of rates of increase, in which matrix estimates are lumped with estimates from population growth rates. 
age- or stage-based projection matrices that indicate the rates at which individuals move between age- or stage-classes, or produce individuals in other classes (Caswell 2001). The finite growth rate is the eigenvalue corresponding to the dominant eigenvector of this matrix, and its logarithm gives the projected rate of increase.

The 'intrinsic rate of increase' $\left(r_{\mathrm{m}}\right)$ is the maximum rate at which the population could increase in defined, usually favourable, circumstances. The intrinsic rate of increase suggests the potential for recovery if optimal conservation measures are implemented. It is usually calculated in a similar way to the projected rate of increase, but replaces observed life-history data with values that might be obtained in favourable conditions.

The observed and projected rates of increase indicate the current health of a population, and should generally be similar to one another (Caughley \& Birch 1971). Consequently, Caughley \& Birch (1971) suggest that calculating the projected rate of increase is seldom worth the labour, at least for large mammals. In this paper we refute this conjecture by calculating observed and projected rates of increase for the same population, showing that they are substantially different, and then discussing the important conservation implications and consequences revealed by this disparity.

Our study species, the sperm whale Physeter macrocephalus, the largest tooth whale (IUCN Red List: Vulnerable), is one of the most ecologically significant vertebrates in the ocean (Clarke 1977), and has been the focus of the whaling industry during 2 major hunts (Starbuck 1878, Tønnessen \& Johnsen 1982). The population biology of the sperm whale is uncertain. Population models were constructed, both during the final phase of commercial sperm whaling in the 1970s and 1980s (e.g. Smith 1977), and, more recently, as concern has grown about issues such as the effects of chemical and noise pollution (Chiquet et al. 2013). However, these models, and especially the earlier ones, suffered from a weak empirical foundation, as there has been an absence of solid systematic data on the life history and population biology of sperm whales.

A distinctive element of the biology of the sperm whale is its social structure, an attribute that we use repeatedly in our analyses. Female and immature sperm whales live and travel in nearly permanent social units, containing, in our study area, an average of about 7 animals (Gero et al. 2014). Maturing male sperm whales disperse from their natal social units, beginning a gradual distributional shift into higher latitude waters that are not used by females (Best 1979).

Over the past 2 decades the sperm whales of the eastern Caribbean have become known individually through collaborative photoidentification efforts, particularly off the islands of Dominica and Guadeloupe (Gero et al. 2014). This population seems to have little connection to other studied populations, of which the closest are those of the Sargasso Sea and Gulf of Mexico (Gero et al. 2007, Engelhaupt et al. 2009), but its geographical extent is unknown. This long-term data set provides an opportunity to address sperm whale population biology empirically. In particular, we can now estimate observed and projected rates of increase for this population, the former by means of a mark-recapture analysis of the individual identifications, and the latter using a 2-stage population model (suckling calves and females/immature animals being the 2 stages).

The analyses reveal a substantial discrepancy between the observed and projected rates of increase. Failing to find methodological explanations for the contrast, we consider the potential scenarios that may have generated this discrepancy. There are conservation implications for the eastern Caribbean sperm whales, and the analysis highlights broader issues for the study of endangered species, such as the presence of unexpected attractive sinks (ecological traps) and the need to examine populations both in terms of numerical trends and internal resilience.

\section{METHODS}

\section{Empirical data}

Seven organizations collected photo-identification data off 6 islands in the Lesser Antilles, eastern Caribbean, between 1984 and 2012, using either research vessels carrying out sperm whale research or commercial whale watch vessels which also focus primarily on tracking sperm whales (details in Gero et al. 2014). The data used in the present paper are summarized in Table 1.

We defined 3 age/sex classes: mature males, distinguished primarily by considerably larger size (greater than $\sim 12 \mathrm{~m}$ ); dependent, small calves that are still suckling and do not make fluke-up foraging dives (see Gero et al. 2013), hereafter referred to as 'calves'; and other animals, immature and adult females, as well as immature males prior to dispersal from their natal social units, hereafter referred to as 
Table 1. Physeter macrocephalus. Number of individual adults identified by year, the number identified by the primary research group (Dalhousie University), and the number of social units identified

\begin{tabular}{|cccc|}
\hline Year & $\begin{array}{c}\text { Adults } \\
\text { identified }\end{array}$ & $\begin{array}{c}\text { By primary } \\
\text { research group }\end{array}$ & $\begin{array}{c}\text { Social units } \\
\text { identified }\end{array}$ \\
\hline 1984 & 13 & 3 & 1 \\
1990 & 1 & 0 & 1 \\
1991 & 1 & 0 & 1 \\
1995 & 65 & 0 & 7 \\
1996 & 36 & 0 & 5 \\
1997 & 1 & 0 & \\
1999 & 9 & 0 & 6 \\
2000 & 17 & 0 & 5 \\
2001 & 27 & 0 & 6 \\
2002 & 8 & 0 & 1 \\
2003 & 30 & 0 & 5 \\
2004 & 14 & 9 & 6 \\
2005 & 106 & 43 & 11 \\
2006 & 80 & 23 & 13 \\
2007 & 75 & 19 & 16 \\
2008 & 105 & 73 & 13 \\
2009 & 71 & 64 & 9 \\
2010 & 56 & 56 & 7 \\
2011 & 54 & 54 & \\
2012 & 42 & 42 & \\
\hline
\end{tabular}

'adults' (we often do not know whether an animal was a female or immature male). In our formulation, calves could, and did, remain calves for $>1$ yr. Data on mature males are extremely limited, and they were not included in any of the analyses in this paper. Adults were identified from photographs of their flukes, and calves from photographs of their dorsal fins and surrounding areas (see Gero et al. 2013). We only considered photographs of quality $Q \geq 3$, using the scale of Arnbom (1987).

Adults and calves were allocated to social units using the criteria described by Gero et al. (2014). The units contained an average of 6.8 (SD 2.8) animals each (Gero et al. 2014). 'Mothers' were assigned to each identified calf using the criteria of Gero et al. (2009).

\section{Population model}

There are 2 classes in the stage-based model, calves and adults, as defined above. We consider time intervals of $1 \mathrm{yr}$. The population model includes 4 parameters:

$\delta_{\mathrm{C}}$, calf mortality, the probability of mortality of a calf per year;

$\delta_{\mathrm{E}}$, effective adult mortality, the probability of mortality of an adult per year. This includes the rate that immature, but weaned, males leave the study area, beginning their dispersal to high latitudes;

$f$, overall fecundity, the probability that an adult gives birth to a calf per year;

$g$, recruitment rate, the probability that a calf becomes an adult during a year given that it survives.

The 2-stage transition matrix for the population is then:

$$
\left[\begin{array}{cc}
\left(1-\delta_{\mathrm{C}}\right)(1-g) & f \\
\left(1-\delta_{\mathrm{C}}\right) g & 1-\delta_{\mathrm{E}}
\end{array}\right]
$$

The dominant eigenvalue of the matrix in Eq. (1) gives the finite growth rate, and its logarithm estimates the population's projected rate of increase $\left(r_{\mathrm{s}}\right)$. The corresponding eigenvector gives the proportions of calves and adults in a population with stable age distribution. We calculate sensitivities, the rates of change of the projected rate of increase per unit change in the life-history parameter, and elasticities, the changes in the projected rate of increase per proportional change in life-history parameter (Caswell 2001). Elasticities are dimensionless indicators of the relative effects of changes in the parameters. In the following subsections we explain how we estimated the 4 constituent parameters of this model: $\delta_{\mathrm{C}}, \delta_{\mathrm{E}}, f$ and $g$.

\section{Estimate of effective mortality of adults: $\delta_{\mathrm{E}}$}

We estimate $\delta_{\mathrm{E}}$ from a likelihood mark-recapture analysis that incorporates the sociality described by Whitehead \& Gero (2014), but using a larger data set (i.e. photo-identifications from additional organizations). The method incorporates a trend, and considers animals associated socially if identified within $2 \mathrm{~h}$ of one another. Confidence intervals and the standard error are estimated using the likelihood support function. For further details, see Whitehead \& Gero (2014).

\section{Estimates of mortality and recruitment of calves: $\delta_{\mathrm{C}}$ and $g$}

We estimate $\delta_{\mathrm{C}}$ and $g$ from the identification histories of known calves and their mothers. In the Supplement at www.int-res.com/articles/suppl/n027 p207_supp.pdf we formulate the log-likelihood of the identification record of calves, conditional on their first identification, and their mothers, with parameters $\delta_{\mathrm{E}}, \delta_{\mathrm{C}}$ and $g$. Using the $\delta_{\mathrm{E}}$ obtained above, $\delta_{\mathrm{C}}$ and recruitment $(g)$ were estimated by maximizing this log-likelihood. 
These estimates assume that if we observe a mother without her calf, then we know the calf has died or emigrated. However, there are years when mothers were identified but their calf was not, even though we know the calf was alive at the time, because it was identified in both previous and subsequent years. All these calf-year anomalies possessed 1 of 2 characteristics: the social unit containing the mother and calf was only observed on a single day that year, or there were no identifications of the unit from the primary research group (Dalhousie University). Thus, we only used calf identifications, or considered that a calf had died or left the area, in years when its mother was identified, members of its unit were identified on 2 or more days, and there were identifications of members of the social unit that year by the primary research group.

\section{Estimate of overall fecundity: $f$}

The proportion of calves in the population was estimated from:

$$
\frac{\sum_{u} \sum_{y} c_{u Y}}{\sum_{u} \sum_{y} a_{u Y}}
$$

where $C_{u y}$ is the number of calves in social unit $u$ in year $y$ and $a_{u y}$ is the number of adults in social unit $u$ in year $y$. These are only counted in years for which the number of adults and calves in the unit could be enumerated accurately (see Gero et al. 2013).

We then estimated overall fecundity, calves produced per adult per year, as:

$f=\frac{\sum_{u} \sum_{Y} c_{u Y}}{\left(\sum_{b=0}^{\infty}\left(1-\delta_{C}\right)^{b}(1-g)^{b}\right) \sum_{u} \sum_{Y} a_{u Y}}=\frac{\left(\delta_{C}+g-\delta_{C} g\right) \sum_{u} \sum_{Y} c_{u Y}}{\sum_{u} \sum_{Y} a_{u Y}}$

The first term in the denominator of the original expression in Eq. (3) is the estimated mean age of unweaned calves.

\section{Measures of precision}

Standard errors and $95 \%$ confidence intervals for the effective adult mortality estimates are from the support function of the mark-recapture with sociality estimate (Whitehead \& Gero 2014). For other parameters of the population model, measures of precision were produced by the block bootstrap procedure, in which data from different social units were sampled with replacement. When needed as input for estimates of calf mortality, recruitment and the parameters of a stable age distribution, estimates of effective adult mortality were introduced as samples from a normal distribution with mean and standard deviation as given by the markrecapture estimates. However, variation in inputeffective adult mortality had no discernible effect on estimates of calf mortality or recruitment obtained using the likelihood method described in the Supplement.

\section{Population size and trajectory}

We estimated the size of the population of adult sperm whales using the study area by means of the photo-identifications collected by various research organizations between 1984 and 2012. Mark-recapture methods, incorporating possible heterogeneity in identification, followed those introduced by Pledger et al. (2003) and used by Gero et al. (2007) on the 1984-2006 section of the data. The analyses produced estimates of the population size in the midpoint of the study (between the 1998 and 1999 field seasons), as well as possible per capita trends in population size, which gave the observed rate of increase $(r)$. In different runs of the model, we considered a stable population, an exponentially growing/declining population, growth/decline with a quadratic term, and a stepped sudden change in population (for some of these models see O'Brien \& Whitehead 2013). The fits of the different models to the data were compared using Akaike's information criterion (AIC), with the best-fitting model being indicated by the lowest value of AIC. Following Gero et al. (2007) we examined the bias in estimates of population size and trend, as well as the validity of the estimates of precision, using a parametric bootstrap, in which 1000 simulated data sets were produced using the chosen model, the estimated parameters and the observed sampling scheme (number of individuals identified each year).

We repeated these mark-recapture estimates using identifications of social units (as designated by Gero et al. 2014), rather than individuals, as the elements of the analysis.

\section{Other parameters}

We estimated the following life-history parameters: first-year mortality, mortality rates of calves between Age 1 and weaning, weaning age, age of dispersal of males, adult mortality (excluding male dispersal), 
age of female sexual maturity, and fecundity of adult females. The derivations of these estimates are explained in the 'Results' section.

\section{RESULTS}

We list all parameter estimates in Table 2, together with standard errors and 95\% confidence intervals, when available.

\section{Estimates of effective mortality, calf mortality, recruitment, overall fecundity}

The estimate of effective adult mortality using the sociality method was derived from 8067 high-quality photo-identifications of 284 individual animals observed between 1984 and 2012. The estimate, which includes dispersal of maturing males, is $\delta_{\mathrm{E}}=$ $0.051 \mathrm{yr}^{-1}$ (95\% CI: 0.022-0.074 $\mathrm{yr}^{-1}$ ).

The estimates of calf mortality and recruitment used 33 individual calves observed in a total of 64 calfyears. Ten of the calves were presumed to die, and 5 to wean. Maximizing the likelihood as formulated in the Supplement, and incorporating the effective adult mortality $\left(\delta_{\mathrm{E}}\right)$ just derived, calf mortality was estimated to be $\delta_{\mathrm{C}}=0.168 \mathrm{yr}^{-1}$ (95\% CI: 0.060-0.350 $\mathrm{yr}^{-1}$ ). From the same analysis, recruitment was estimated to be $g$ $=0.105 \mathrm{yr}^{-1}\left(95 \% \mathrm{CI}: 0.029-0.188 \mathrm{yr}^{-1}\right)$. These estimates were entirely unaffected by the value of $\delta_{\mathrm{E}}$ input into the likelihood equations.

We had accurate counts of the numbers of adults and calves in units for a total of 62 unit-years. Summing over these gave 69 calves and 283 adults, and, thus, using Eq. (2), we estimate the proportion of calves in the population to be 0.244 (95\% CI: 0.170-0.311). Using Eq. (3) and the estimates of $\delta_{C}$ and recruitment $(g)$ just derived gave an estimated overall fecundity (calves/adult $\mathrm{yr}^{-1}$ ) of $f=0.062 \mathrm{yr}^{-1}$ (95\% CI: 0.038-0.089 $\mathrm{yr}^{-1}$ ).

\section{Long-term properties}

The estimates of $\delta_{\mathrm{E}}, \delta_{\mathrm{C}}, g$, and $f$ gave a stage transition matrix (Eq. 1):

$$
\left[\begin{array}{ll}
0.7451 & 0.0621 \\
0.0870 & 0.9495
\end{array}\right]
$$

The logarithm of the principal eigenvalue of this matrix suggested a long-term population decline (projected rate of increase) of $r_{\mathrm{s}}=-2.7 \% \mathrm{yr}^{-1}(95 \%$ CI: -5.4 to $-0.4 \% \mathrm{yr}^{-1}$ ), with the stable proportion of calves in the population equal to 0.214 (95\% CI: $0.157-0.287$ ).

Table 2. Physeter macrocephalus. Population and life-history parameter estimates for eastern Caribbean sperm whales, indicating the method used to calculate standard errors and confidence intervals

\begin{tabular}{|c|c|c|c|c|c|c|}
\hline \multirow[b]{2}{*}{ Effective adult mortality $\left(\mathrm{yr}^{-1}\right)$} & \multirow[b]{2}{*}{$\delta_{\mathrm{E}}$} & \multirow{2}{*}{$\frac{\text { Estimate }}{0.0505}$} & \multirow{2}{*}{$\frac{\mathrm{SE}}{0.0114}$} & \multicolumn{2}{|c|}{$-95 \% \mathrm{CI}-$} & \multirow{2}{*}{$\begin{array}{c}\text { Method } \\
\text { Likelihood }\end{array}$} \\
\hline & & & & 0.0217 & 0.0738 & \\
\hline Calf mortality $\left(\mathrm{yr}^{-1}\right)$ & $\delta_{\mathrm{C}}$ & 0.1679 & 0.0764 & 0.0599 & 0.3502 & Block bootstrap \\
\hline Recruitment rate $\left(\mathrm{yr}^{-1}\right)$ & $g$ & 0.1045 & 0.0408 & 0.0286 & 0.1878 & Block bootstrap \\
\hline Overall fecundity $\left(\mathrm{yr}^{-1}\right)$ & $f$ & 0.0621 & 0.0133 & 0.0379 & 0.0894 & Block bootstrap \\
\hline Proportion calves & & 0.2438 & 0.0354 & 0.1699 & 0.3108 & Block bootstrap \\
\hline \multicolumn{7}{|c|}{ Estimates from stage-based transition matrix } \\
\hline Projected rate of increase $\left(\mathrm{yr}^{-1}\right)$ & $r_{\mathrm{s}}$ & -0.0271 & 0.0131 & -0.0542 & -0.0040 & Block bootstrap \\
\hline Proportion calves & & 0.2141 & 0.0361 & 0.1569 & 0.2865 & Block bootstrap \\
\hline \multicolumn{7}{|l|}{ Derived parameters } \\
\hline First-year mortality $\left(\mathrm{yr}^{-1}\right)$ & $\delta_{\mathrm{C} 1}$ & 0.2941 & 0.1105 & 0.1031 & 0.5596 & Binomial \\
\hline Mortality 2nd year-weaning $\left(\mathrm{yr}^{-1}\right)$ & $\delta_{\mathrm{C} 2+}$ & 0.3095 & - & - & - & - \\
\hline Adult mortality $\left(\mathrm{yr}^{-1}\right)$ & $\delta_{\mathrm{A}}$ & 0.0331 & 0.0105 & 0.0181 & 0.0587 & Simulation \\
\hline Weaning age (yr) & $w$ & 5 & - & - & - & - \\
\hline Male dispersal post-weaning (yr) & $d$ & 10 & - & - & - & - \\
\hline Weaning to first birth, females (yr) & $m$ & 3 & - & - & - & - \\
\hline Adult female fecundity $\left(\mathrm{yr}^{-1}\right)$ & $f_{\mathrm{AF}}$ & 0.0883 & 0.0214 & 0.0478 & 0.1323 & Simulation \\
\hline \multicolumn{7}{|l|}{ Population analysis } \\
\hline Population 1998/1999 (no. of adults) & & 156.2 & 18.3 & 126.5 & 195.0 & Bootstrap \\
\hline Trend (observed rate of increase) $\left(\mathrm{yr}^{-1}\right)$ & $r$ & 0.0335 & 0.0122 & 0.0099 & 0.0568 & Bootstrap \\
\hline Unit population 1998/1999 (units) & & 11.5 & 2.4 & 4.9 & 14.5 & Bootstrap \\
\hline Trend: units $\left(\mathrm{yr}^{-1}\right)$ & $r_{\mathrm{UNITS}}$ & 0.0229 & 0.0178 & -0.0062 & 0.0631 & Bootstrap \\
\hline
\end{tabular}


Sensitivities and elasticities are shown numerically and graphically in Fig. 1. In explanation, a sensitivity of -0.910 for adult mortality implies that if adult mortality is reduced by $0.01 \mathrm{yr}^{-1}$ then the projected rate of increase is augmented by $0.91 \%$, and an elasticity of -0.041 implies that if the adult mortality is decreased by $10 \%$ then the projected rate of increase is augmented by $0.41 \%$. Adult mortality has the largest effect on our calculations of sensitivity and elasticity for the projected rate of increase (Fig. 1). In order to produce a positive projected rate of increase, effective adult mortality needs to be substantially lower.

\section{Population size and trend}

The best-fitting population model (Table 3), which included heterogeneity in identification, had a simple exponential trend, or observed rate of increase of
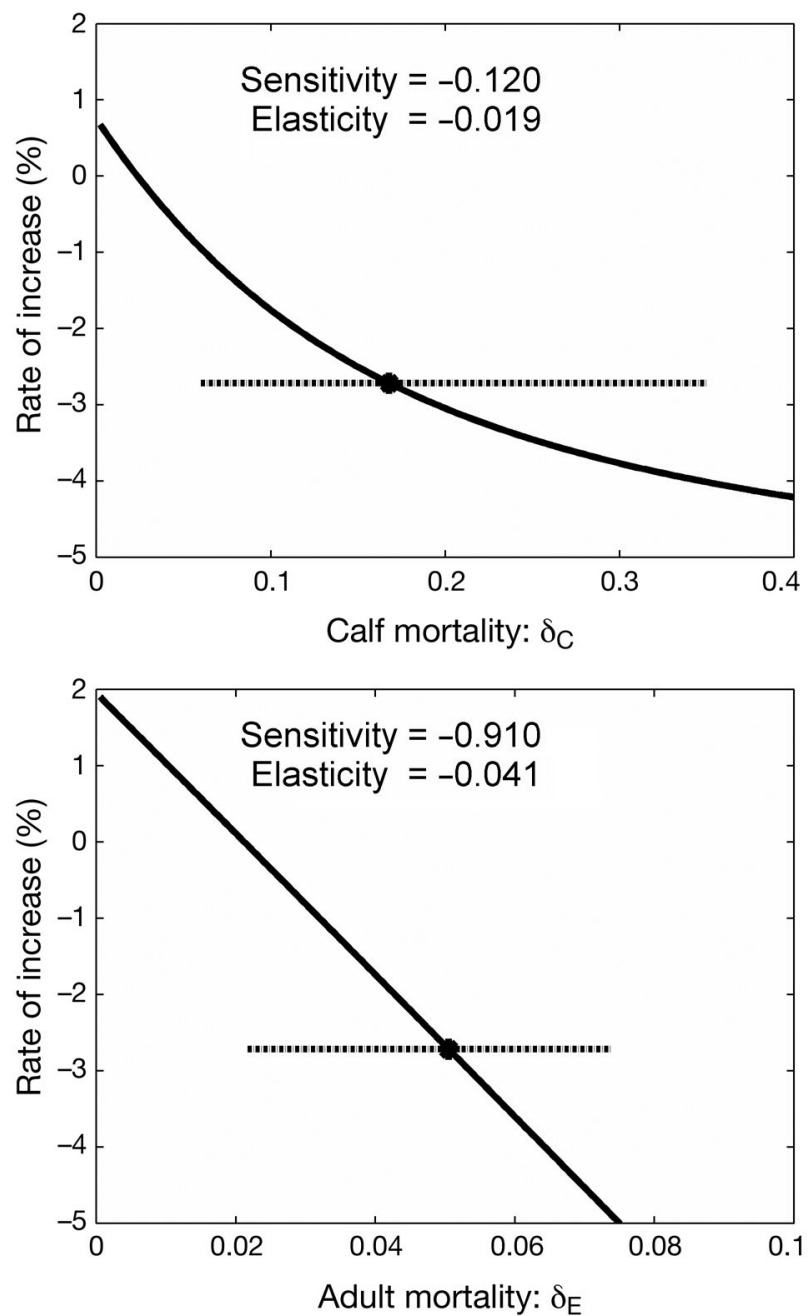

Table 3. Physeter macrocephalus. Fits of different population models for individuals and social units, excluding or including heterogeneity in identification, and without trend or with a simple constant trend, quadratic trend, or sudden change in population size, as indicated by Akaike's information criterion (AIC)

\begin{tabular}{|lccc|}
\hline Heterogeneity & Model & AIC & \multicolumn{1}{c|}{$\Delta$ AIC } \\
\hline Individuals & & & \\
No & Stable & 1934.76 & 121.06 \\
No & Trend & 1930.87 & 117.17 \\
Yes & Stable & 1820.11 & 6.41 \\
Yes & Trend & 1813.70 & 0.00 \\
Yes & Trend (quadratic) & 1815.70 & 2.00 \\
Yes & Step & 1817.24 & 3.54 \\
Units & & & \\
No & Stable & 231.49 & 25.19 \\
No & Trend & 231.58 & 25.28 \\
Yes & Stable & 206.44 & 0.14 \\
Yes & Trend & 206.30 & 0.00 \\
Yes & Trend (quadratic) & 208.30 & 2.00 \\
Yes & Step & 208.29 & 1.99 \\
\hline
\end{tabular}
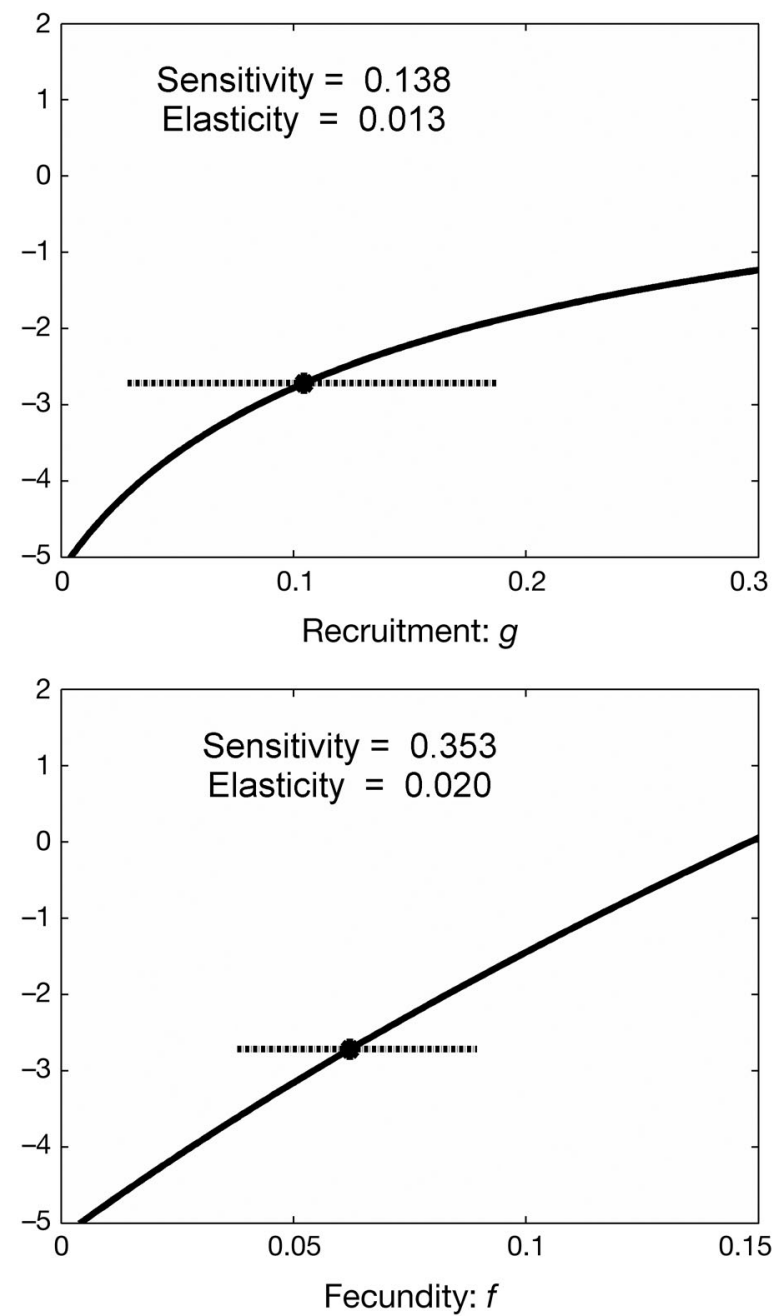

Fig. 1. Sensitivities and elasticities of the projected rate of increase to the 4 input life-history parameters. The best empirical estimate of each parameter is indicated by a filled circle, and its $95 \%$ confidence interval by a horizontal dashed line 
$r=+3.4 \% \mathrm{yr}^{-1}\left(95 \%\right.$ CI: $\left.1.0-5.7 \% \mathrm{y}^{\mathrm{r}-1}\right)$, with a population of 156.2 adults (95\% CI: 126.5-195.0) in 1998 (Table 2). This suggests an increase from about 118 adults in 1990 to 245 in 2012. The parametric bootstrap indicated little bias $(<5 \%)$ in either the estimate of population size or that of trend, and that the nonparametric bootstrap estimates of confidence are reasonable (although perhaps a little narrow in the case of population size). Analysis using social units also selected the best fitting model including an increasing trend of $r=+2.3 \% \mathrm{yr}^{-1}$ increase $(95 \% \mathrm{CI}$ : -0.6 to $\left.6.3 \% \mathrm{yr}^{-1}\right)$, with a population of 11.5 units $(95 \% \mathrm{CI}$ : 4.9-14.5) in 1998. However, in this case, a model without a trend also had considerable support ( $\triangle \mathrm{AIC}$ $=0.14$ ).

\section{Other population parameters}

First-year mortality. There are 22 calves for which we have a presumed year of birth, as either their mothers were observed without them the previous year or the calf was very small when observed. Of these, 12 were identified in later years with their mothers, 5 were not seen in later years, but their mothers were identified without them, and, for 5, neither they, nor their mothers were later observed. This suggests a mortality between first observation and 1 yr later of $\delta_{\mathrm{C} 1}=5 / 17=0.294$ (95\% CI: 0.103-0.560, using binomial distribution). This will be an underestimate of first-year mortality, as it excludes perinatal mortality (we observed no births).

Mortality of calves between Age 1 and weaning. Only 1 calf of known age is known to have died after their first year but before weaning. Using the same likelihood method (in the Supplement) as used to calculate overall calf mortality but only entering data from the second observation of each calf (i.e. excluding first-year calves) indicated a mortality of calves between Age 1 and weaning of $\delta_{\mathrm{C} 2+}=0.040 \mathrm{yr}^{-1}$. We do not have sufficient data to give useful meaningful confidence intervals for this estimate. However, we note that it is similar to the estimated adult mortality.

Weaning age. There are 3 calves with sighting records that bear directly on the age at weaning: \#57231 who weaned at an age of 5 yr (possibly 6), \#6035 who weaned at an age of at least $5 \mathrm{yr}$, and \#5701 who weaned at an age of at least 3 yr. There are also 4 calves who suckled over at least a $4 \mathrm{yr}$ period, and 2 who suckled over at least a $5 \mathrm{yr}$ period. These data are most consistent with a mean weaning age of approximately $5 \mathrm{yr}$.
Dispersal of males. We have very limited information on the dispersal of males. One male, \#5727, with an estimated birth date between 1995 and 1997 was partially dispersed in 2012 - he was rarely with his natal social unit, but was still using eastern Caribbean waters (Gero et al. 2013) - and was roughly 15 to $17 \mathrm{yr}$ of age or 9 to $11 \mathrm{yr}$ post-weaning.

Adult mortality. If the sex ratio at birth is equal (Best et al. 1984), and males and females have equal calf and adult mortalities until the males disperse, $d$ years after weaning, the effective adult mortality $\left(\delta_{\mathrm{E}}\right)$ is related to the actual adult mortality (excluding male dispersal), $\delta_{\mathrm{A}}$, by:

$\delta_{\mathrm{E}}=\frac{\sum_{y=0}^{\infty} \delta_{\mathrm{A}}\left(1-\delta_{\mathrm{A}}\right)^{y}+\sum_{y=0}^{d-1} \delta_{\mathrm{A}}\left(1-\delta_{\mathrm{A}}\right)^{y}+\left(1-\delta_{\mathrm{A}}\right)^{d}}{\sum_{y=0}^{\infty}\left(1-\delta_{\mathrm{A}}\right)^{y}+\sum_{y=0}^{d}\left(1-\delta_{\mathrm{A}}\right)^{y}}=\frac{2 \delta_{\mathrm{A}}}{2-\left(1-\delta_{\mathrm{A}}\right)^{d+1}}$

We then numerically solved Eq. (4) for $\delta_{\mathrm{A}}$. We estimated the precision of this estimate by simulating (1000 runs), with $\delta_{\mathrm{E}}$ chosen from the normal distribution (with estimated mean and SE in Table 2 as mean and $\mathrm{SD}$ ) and $d$ from the normal distribution (mean: $10 \mathrm{yr}$, SD: $2.5 \mathrm{yr}$ ). Using this process, we estimate adult mortality to be $\delta_{\mathrm{A}}=0.033 \mathrm{yr}^{-1}$ (95\% CI: $0.0 .018-0.059$ $\mathrm{yr}^{-1}$ ). This estimate has rather little dependence on the input age of male dispersal: using $d=5$ yr gave $\delta_{\mathrm{A}}=$ $0.029 \mathrm{yr}^{-1}$, while using $d=15 \mathrm{yr}$ gave $\delta_{\mathrm{A}}=0.037 \mathrm{yr}^{-1}$.

Female sexual maturity. We have very limited information on female sexual maturity. One female (\#6035), weaned in 2010, may have given birth in 2013, suggesting an age of first birth of about 9 yr.

Fecundity of adult females. We can translate the estimate of overall fecundity, $f$, into an estimate for adult females, $f_{\mathrm{AF}}$, by:

$$
\begin{gathered}
f=\frac{\sum_{y=m}^{\infty} f_{\mathrm{AF}}\left(1-\delta_{\mathrm{A}}\right)^{y}}{\sum_{y=0}^{\infty}\left(1-\delta_{\mathrm{A}}\right)^{y}+\sum_{y=0}^{d}\left(1-\delta_{\mathrm{A}}\right)^{y}} \\
f=\frac{f_{\mathrm{A}} \delta_{A}\left(1-\delta_{\mathrm{A}}\right)^{m}}{\delta_{\mathrm{A}}+\delta_{\mathrm{A}}\left(1-\left(1-\delta_{\mathrm{A}}\right)^{d}\right)} \\
f_{\mathrm{AF}}=f \frac{2-\left(1-\delta_{\mathrm{A}}\right)^{d}}{\left(1-\delta_{\mathrm{A}}\right)^{m}}
\end{gathered}
$$

where $m$ is the number of years past weaning when a female first gives birth. As with estimated adult mortality, we used simulation to obtain confidence intervals. In this case, we assumed normal distributions, with mean values and standard deviations for $f$ and $\delta_{\mathrm{A}}$ as in Table 2 (using rough estimates of standard errors as standard deviations $), d \sim \mathrm{N}(10,2.5)$ and $m \sim \mathrm{N}(4,1)$. This gives an estimated adult female fecundity of $f_{\mathrm{AF}}=0.085$ calves per mature female per year (95\% CI: 0.045-0.132). This estimate excludes calves that died very soon after birth. 


\section{DISCUSSION}

The 2 rates of increase that we have calculated for eastern Caribbean sperm whales tell conflicting stories. The observed rate of increase $(r)$ is positive, with a $95 \%$ confidence interval entirely above zero. The projected rate of increase $\left(r_{\mathrm{s}}\right)$ is negative, with a $95 \%$ confidence interval entirely below zero. We will consider these estimates separately, then attempt to reconcile them. Finally, we will discuss implications for the conservation of this small population, and more generally for studies of endangered species. (In the Supplement we include a technical discussion of the other estimates of sperm whale population parameters listed in Table 2.)

\section{Observed rate of increase}

The calculated observed rate of increase of eastern Caribbean sperm whales is $r=+3.4 \% \mathrm{yr}^{-1}(95 \% \mathrm{CI}$ : $1.0-5.7 \% \mathrm{yr}^{-1}$ ). This is a little higher than estimates of the maximal, or intrinsic, rate of increase for sperm whales $\left(r_{\mathrm{m}}=0.9 \% \mathrm{yr}^{-1}\right)$ calculated (Whitehead 2003) using the International Whaling Commission's (1980) life-history parameter estimates; $r_{\mathrm{m}}=1.1 \% \mathrm{yr}^{-1}$ calculated (Whitehead 2003) using age-specific mortality rates of the killer whales Orcinus orca (Olesiuk et al. 1990) and pregnancy rates from South African scientific sperm whale catches (Best et al. 1984); or $r_{\mathrm{m}}=$ $1.0 \% \mathrm{yr}^{-1}$ from a recently published, stage-structured population model (Chiquet et al. 2013), using a variety of input data. These estimates of intrinsic rate of increase use various life-history data, some more reliable than others, but they are remarkably consistent. Using 'all the best-case' parameters, Chiquet et al. (2013) were able to achieve an intrinsic rate of increase of $r_{\mathrm{m}}=3.0 \% \mathrm{yr}^{-1}$. From this perspective, our estimate of an increase of $3.4 \% \mathrm{yr}^{-1}$ seems good news: a population, following some unknown level of depletion (unknown because of uncertainties as to catches, population sizes and the geographical ranges of the animals) by pelagic- and shore-based, open-boat whalers over the past 250 yr (Reeves \& Smith 2006), is now increasing at close to its maximal potential rate.

We were concerned that this result might be, at least partially, an artifact of a highly non-uniform pattern of photo-identification effort among years (Table 1). Effort increased over the study period, as did the apparent population size. While the amount of effort increased in 2005, its geographic extent did not, being almost entirely concentrated in the waters leeward of Dominica and Guadeloupe both before and after 2005. However, if individuals, or social units, varied in their identifiability, this could lead to a negative bias in years of low effort, as the less easily identified animals would tend to only be identified in years of high effort. Our use of mark-recapture methods that include heterogeneity in identifiability should have removed this problem, but, in the absence of detailed simulation studies, we cannot be sure that it fully did so. However, we note 3 lines of evidence suggesting that the positive observed trend is real:

(1) A population model including a sudden increase in population size in 2005, with the onset of yearly dedicated research effort, was less well supported than a constant per capita trend (Table 3).

(2) Simple Petersen 2-sample mark-recapture estimates using samples from adjacent years gave a lower population estimate for 1995-1996, the only high-effort period of the 1990s (92.9 adults), than for any of the seven 2 yr periods after 2005 (119.7-185.1 adults).

(3) The analysis using social units also indicated a positive trend, of similar magnitude, although the level of support was less strong (Table 2).

A final caveat in the trend analysis is that the bootstrap calculation of confidence intervals of the parameter estimates assumes independence of individuals, and because female sperm whales travel in permanent social units, the members of which have correlated sighting histories, this is not strictly true. We cannot use the block bootstrap as in the estimation of life-history parameters, because not all individuals in the population analysis were assigned to social units. Thus, the confidence interval for the population size and the trend for individuals may appear overly precise in Table 1 . This is not a problem for the analysis of social units, and that analysis also supports - although less strongly - a population increase.

Despite the caveats just discussed, we interpret the mark-recapture analyses as supporting an increase in the sperm whale population using the eastern Caribbean, both in the number of adults and the number of social units.

\section{Projected rate of increase (finite growth rate)}

Our estimate of $r_{\mathrm{s}}=-2.7 \% \mathrm{yr}^{-1}(95 \%$ CI: -5.4 to $-0.4 \% \mathrm{yr}^{-1}$ ) is a function of the 4 population parameters input into the transition matrix: the calf mortality, effective adult mortality, recruitment, 
and fecundity rates. These are all estimated directly from empirical data: the rates at which adults and calves disappeared from the identification record, that calves became adults, and that units contained calves. Biases would appear if there were systematic misrepresentations of these events. While there may have been errors in identifying when calves were weaned, we suspect that they were not overtly biased, and, even if they were, this would effectively only slightly shift the division between the 2 stages, adults and calves, and likely only make small changes in the resultant population projections. Biases in mortality are potentially more serious, and are likely to be positive: in photo-identification studies it is very unlikely that a dead animal will be identified, but it is quite conceivable that a living animal will be misidentified. If marks change so radically that an animal becomes unidentifiable, then this will become a case of effective mortality, increasing calculated mortality rates and lowering estimated projected rates of increase. While this an important issue in population studies of cetaceans (see Hammond 1986), we believe it is of minor significance in our study, as both adult and calf mortalities were inferred from the social context. While an identification technician may miss or mistake an identification when comparing it with a catalogue of thousands, when the identification is viewed within the context of 5 to 12 close companions this is highly unlikely. The mortality estimations also incorporate potential variation in identifiability between individuals (for adults) and social units (for calves). Thus, we do not think our estimates of any of the input parameters of the population model are seriously biased.

The model itself is a simplification, particularly in agglomerating all sperm whales except adult males, into just 2 stages: adults and calves. Mortality and fecundity will differ between ages and sexes within these stages. This means that the life-history parameters used in the model do not exactly correspond to their more generally used versions, and the simplification will affect the transient dynamics of the system, as well as possibly amplifying the effects of adult mortality on the system (for instance if older animals have high mortality but low fecundity). However, the input parameters were calculated specifically from animals of the defined stages, and so, if the proportions of animals in the 2 stages are as predicted by the transition matrix, as they are (Table 2), the population should be trending as indicated by $r_{\mathrm{s}}$. But it is not.

\section{Conflicting rates of increase}

As suggested in the previous sections, we do not think there are serious biases in the estimates of observed and projected rates of increase. The sensitivity and elasticity analyses for the projected rate of increase suggest that the calf mortality and recruitment rates have rather little bearing on the calculated rate (Fig. 1). The overall fecundity has some effect, but the calculated fecundity would have to be very much greater than that measured to produce a growing population. Adult mortality seems to be the key parameter in both our analyses (Fig. 1) and in that of Chiquet et al. (2013). Adult mortality has to be well reduced below our estimate of $0.033 \mathrm{yr}^{-1}$ for a sustainable population.

Our analysis, as well as those of Chiquet et al. (2013) and Whitehead (2003), emphasizes the fragility of sperm whale population dynamics. Even with optimal life-history parameters, the potential rate of increase is small. In the case of eastern Caribbean sperm whales the population model strongly suggests that current adult mortality is too high to permit a sustainable population.

But why, then, is the population rising? We think the most plausible explanation is that social units, and, thus, their members, are increasingly using eastern Caribbean waters. There are several possible scenarios as to why, over the past 20 or so years, animals from elsewhere have begun to use, or increasingly use, the waters along the Lesser Antillean chain. It seems unlikely that this is to escape disturbance, as the Antillean waters are likely to have more commercial and recreational ship traffic, noise, and other anthropogenic disturbance than any fairly proximate donor sperm whale habitat, except possibly the Gulf of Mexico. But there are no photo-identification matches between the Gulf of Mexico and the eastern Caribbean (Gero et al. 2007). More likely is that current and recent foraging potential is better in the eastern Caribbean than elsewhere, and so, following a scenario of density-dependent habitat selection (e.g. Whitehead 2000), there is net movement into these more favourable waters. Immigration to the eastern Caribbean could be occurring because of poor conditions elsewhere, perhaps a sudden effect, as when eastern Pacific sperm whales respond to El Niño-Southern Oscillation events by movement (Ramirez \& Urquizo 1985), or due to a gradual shift in relative suitability.

The naturally negative growth rate of the eastern Caribbean population might exacerbate this if densitydependent processes are occurring. In this scenario, 
the eastern Caribbean acts as a population sink, with good food resources attracting immigrants, but high mortality keeping the population from increasing too rapidly and the resources from being depleted. The eastern Caribbean then becomes an attractive sink (Delibes et al. 2001), a preferred habitat within which life-history characteristics are negative, also called an ecological trap (Battin 2004).

\section{Conservation consequences}

Attractive sinks are a major concern in conservation biology (Battin 2004), potentially dragging populations towards extinction (Delibes et al. 2001). Identifying such sinks and mapping them can lead directly to effective management recommendations, as in the case of grizzly bears Ursus arctos in the central Rockies for whom areas around townships constitute attractive sinks (Nielsen et al. 2004). In direct parallel with our hypothesis for the sperm whales of the eastern Caribbean, the attractive sinks for grizzly bears are the result of elevated mortality from anthropogenic causes (Nielsen et al. 2004).

Why is there so much mortality in the eastern Caribbean? The waters off the islands of the Lesser Antilles are heavily used by humans, with much shipping of various kinds, including cargo vessels, cruise ships, and high-speed ferries. Collisions with high-speed ferries have been shown to be especially lethal for sperm whales in proximity to archipelagos (Carrillo \& Ritter 2010). Ship noise can also increase the stress response in cetaceans (Rolland et al. 2012) and lead to lower foraging efficiency in deep-diving toothed whales, as it masks their echolocation (Aguilar Soto et al. 2006). As such, the impacts of repeated and chronic shipping noise are likely great, but the mechanisms behind any potential mortality remain poorly understood (Weilgart 2007).

There is also substantial fishing in the habitat of the sperm whales of the eastern Caribbean. While much of the fishing uses small-scale light gear, some types like gillnets are a source of cetacean mortality in the Wider Caribbean Region (Vidal et al. 1994) and have caused fatal entanglements of sperm whales (Haase \& Félix 1994). The common use of fish-aggregating devices off the Caribbean islands creates a scenario in which drifting gear, nets, and line are present even in the offshore habitat of sperm whales (FAO 2002). Marine debris, particularly remains of fishing nets and plastic bags, are an additional cause of sperm whale mortality (Jacobsen et al. 2010), and the United Nation's Caribbean Environmental Program cites pollution and marine debris as principal threats to marine mammals in the Caribbean.

The Caribbean islands and other archipelagos constitute the more urban areas of sperm whale habitat, with generally greater potential anthropogenic impacts. Furthermore, there is little capacity to document mortality in the Caribbean; as a result, a focus on reports of dead animals will likely end up underestimating mortality in this area (Williams et al. 2011). Therefore, close monitoring of this population, development of stranding networks, and, especially, the reduction of the potential causes of sperm whale mortality should be goals for management. In a complex, multinational management area, like the Wider Caribbean Region, no one country will be able to monitor and mitigate concerns in isolation. Given the ranging patterns of this species, threats to this population in one national jurisdiction will be threats to the animals in the next, and, as such, sperm whales must be considered as a cross-border species of concern and managed under international agreements.

\section{CONCLUSIONS}

The sperm whale population of the eastern Caribbean looks healthy from a numeric perspective, increasing at about $3.4 \% \mathrm{yr}^{-1}$. But our analysis at an individual level presents a different picture: mortality is not compensated by fecundity. The eastern Caribbean seems to be a population sink, with anthropogenic mortality tipping the very finely balanced scales of sperm whale population biology. This case study highlights the importance of analysing populations with multiple methodologies, especially using individual-level empirical data from longitudinal monitoring.

Our analysis of this population shows that a positive observed rate of increase is not necessarily a sign of a healthy population. Contra Caughley \& Birch (1971), calculating the projected rate of increase of a population of large mammals, especially if an endangered species, may be insightful. When projected and observed rates of increase agree, this adds considerable support to conclusions that a population is recovering (for positive rates), or still on the path to extinction (for negative rates). When, as in our sperm whale study, the projected and observed rates of increase differ, the first step is to consider carefully any methodological issues in calculating the 2 rates of increase that could explain the discrepancy. If the difference is not a result of methodology or of transient dynamics, the strong indication is that the study 
is not addressing a discrete population, i.e. that the study area is part of a larger network, perhaps with source-sink relationships. If the observed rate is higher than the projected rate, then the study appears to be addressing an attractive element of a metapopulation system, whereas if the projected rate is higher, then the study population would appear to be a source. Identifying adaptive sinks is challenging (Battin 2004), and a comparison of rates of increase does not provide definitive proof; however, it does, as in the case of Caribbean sperm whales, highlight the need for wide-scale studies of movements, habitat use, and life history.

Acknowledgements. Our research in Dominica was carried out under scientific research permits: SCR 013/05-02, RP2/12 IW-1, RP-09/ 014 IW-1, RP-01/079W-2, and RP03/059W-4. The following organizations each contributed $<5 \%$ of the photo-identifications used in this analysis (in order of greatest contributions): Association Evasions Tropical, Guadeloupe; Anchorage Whalewatch, Dominica; The International Fund For Animal Welfare (IFAW), USA; The Society for Dolphin Conservation, Germany; Woods Hole Oceanographic Institution (WHOI), USA; Ocean Research and Education Society, USA; and SeaWatch Foundation (SWF), UK. We thank all crew members of the RV 'Balaena'; the crew of RV 'Rambler'; the crews of RV 'Song of the Whale'; the crews of AET's SV 'Tzigane IV'; all the crews of the whale watch vessels off Dominica, in particular P. Charles and P. Francis, who collected the identifications used here; the staff at the Anchorage Hotel and Dive Center and W.E.T. Dominica for logistical support over the years. D. Perryman and the staff of Dive Dominica greatly helped SWF while in Dominica, as well as the IFAW crews during research. WHOI research was conducted under NMFS Permit 573 and funding came from the Laurel Foundation, National Geographic Society, and NSF BNS 85-08047. Our fieldwork was supported by operating and equipment grants to H.W. from the Natural Sciences and Engineering Research Council of Canada (NSERC) and the Whale and Dolphin Conservation Society. S.G. was supported during the course of the study by an NSERC Postgraduate Scholarship (PGS-M), an NSERC Canadian Graduate Scholarship (CGS-D), a Killam predoctoral scholarship, the Patrick F. Lett Fund, and Dalhousie University's President's Award. Thanks to 2 anonymous reviewers for constructive comments. This study emanates from The Dominica Sperm Whale Project: www.thespermwhaleproject.org

\section{LITERATURE CITED}

Aguilar Soto N, Johnson M, Madsen PT, Tyack PL, Bocconcelli A, Borsani FJ (2006) Does intense ship noise disrupt foraging in deep diving Cuvier's beaked whales (Ziphius cavirostris)? Mar Mamm Sci 22:690-699

Arnbom T (1987) Individual identification of sperm whales. Rep Int Whaling Comm 37:201-204

Battin J (2004) When good animals love bad habitats: ecological traps and the conservation of animal populations. Conserv Biol 18:1482-1491
Best PB (1979) Social organization in sperm whales, Physeter macrocephalus. In: Winn HE, Olla BL (eds) Behavior of marine animals. Plenum, New York, NY

Best PB, Canham PAS, Macleod N (1984) Patterns of reproduction in sperm whales, Physeter macrocephalus. Rep Int Whaling Comm Spec Issue 6:51-79

Carrillo M, Ritter F (2010) Increasing numbers of ship strikes in the Canary Islands: proposals for immediate action to reduce risk of vessel-whale collisions. J Cetacean Res Manag 11:131-138

Caswell H (2001) Matrix population models: construction, analysis, and interpretation, 2nd edn. Sinauer Associates, Sunderland, MA

> Caughley G, Birch L (1971) Rate of increase. J Wildl Manag 35:658-663

> Chiquet RA, Ma B, Ackleh AS, Pal N, Sidorovskaia N (2013) Demographic analysis of sperm whales using matrix population models. Ecol Modell 248:71-79

Clarke MR (1977) Beaks, nets and numbers. Symp Zool Soc London 38:89-126

Delibes M, Gaona P, Ferreras P (2001) Effects of an attractive sink leading into maladaptive habitat selection. Am Nat 158:277-285

Engelhaupt D, Hoelzel AR, Nicholson C, Frantzis A and others (2009) Female philopatry in coastal basins and male dispersion across the North Atlantic in a highly mobile marine species, the sperm whale (Physeter macrocephalus). Mol Ecol 18:4193-4205

Fagan WF, Lynch HJ, Noon BR (2010) Pitfalls and challenges of estimating population growth rate from empirical data: consequences for allometric scaling relations. Oikos 119:455-464

FAO (Food and Agriculture Organization) (2002) First meeting of the WECAFC ad hoc working group on the development of sustainable moored fish aggregating device fishing in the Lesser Antilles. FAO Fisheries Report No. 683, SLAC/R683 Suppl, FAO, Rome

Gero S, Gordon J, Carlson C, Evans P, Whitehead H (2007) Population estimate and inter-island movement of sperm whales, Physeter macrocephalus, in the eastern Caribbean. J Cetacean Res Manag 9:143-150

> Gero S, Engelhaupt D, Rendell L, Whitehead H (2009) Who cares? Between-group variation in alloparental caregiving in sperm whales. Behav Ecol 20:838-843

Gero S, Gordon J, Whitehead H (2013) Calves as social hubs: dynamics of the social network within sperm whale units. Proc R Soc B 280:20131113

> Gero S, Milligan M, Rinaldi C, Francis P and others (2014) Behavior and social structure of the sperm whales of Dominica, West Indies. Mar Mamm Sci 30:905-922

Haase B, Félix F (1994) A note on the incidental mortality of sperm whales (Physeter macrocephalus) in Ecuador. Rep Int Whaling Comm Spec Issue 15:481-483

Hammond PS (1986) Estimating the size of naturally marked whale populations using capture-recapture techniques. Rep Int Whaling Comm Spec Issue 8:253-282

International Whaling Commission (1980) Report of the Special Meeting on Sperm Whale Assessments, La Jolla, 27 November to 8 December 1978. Rep Int Whaling Comm Spec Issue 2:107-136

> Jacobsen JK, Massey L, Gulland F (2010) Fatal ingestion of floating net debris by two sperm whales (Physeter macrocephalus). Mar Pollut Bull 60:765-767

Nielsen SE, Herrero S, Boyce MS, Mace RD, Benn B, Gibeau ML, Jevons S (2004) Modelling the spatial distribution of 
human-caused grizzly bear mortalities in the Central Rockies ecosystem of Canada. Biol Conserv 120:101-113

O'Brien K, Whitehead H (2013) Population analysis of Endangered northern bottlenose whales on the Scotian Shelf seven years after the establishment of a Marine Protected Area. Endang Species Res 21:273-284

Olesiuk P, Bigg MA, Ellis GM (1990) Life history and population dynamics of resident killer whales (Orcinus orca) in the coastal waters of British Columbia and Washington State. Rep Int Whaling Comm Spec Issue 12:209-243

Pereira HM, Daily GC, Roughgarden J (2004) A framework for assessing the relative vulnerability of species to landuse change. Ecol Appl 14:730-742

Pledger S, Pollock KH, Norris JL (2003) Open capturerecapture models with heterogeneity. I. Cormack-JollySeber model. Biometrics 59:786-794

Ramirez P, Urquizo W (1985) Los cetaceos mayores y el fenómeno 'El Niño' 1982-83. In: Arntz W, Landa A, Tarazona J (eds) El fenómeno El Niño y su impacto en la fauna marina. Boletin Instituto del Mar Peru Spec Issue: 201-206

Reeves RR, Smith TD (2006) A taxonomy of world whaling. In: Estes JA, DeMaster DP, Doak DF, Williams TM, Brownell RL (eds) Whales, whaling, and ocean ecosystems. University of California Press, Berkeley, CA

Rolland RM, Parks SE, Hunt KE, Castellote M and others (2012) Evidence that ship noise increases stress in right

Editorial responsibility: Nils Bunnefeld, Stirling, UK whales. Proc R Soc B 279:2363-2368

Smith TD (1977) A matrix model of sperm whale populations. Rep Int Whaling Comm 27:337-342

Starbuck A (1878) History of the American whale fishery from its earliest inception to the year 1876. Government Printing Office, Washington, DC

Tønnessen JN, Johnsen AO (1982) The history of modern whaling. University of California Press, Berkeley, CA

Vidal O, Van Waerebeek K, Findley LT (1994) Cetaceans and gillnet fisheries in Mexico, Central America, and the Wider Caribbean: a preliminary review. Rep Int Whaling Comm Spec Issue 15:221-233

Weilgart LS (2007) The impacts of anthropogenic noise on cetaceans and implications for management. Can J Zool 85:1091-1116

Whitehead H (2000) Density-dependent habitat selection and the modeling of sperm whale (Physeter macrocephalus) exploitation. Can J Fish Aquat Sci 57:223-230

Whitehead H (2003) Sperm whales: social evolution in the ocean. Chicago University Press, Chicago, IL

Whitehead H, Gero S (2014) Using social structure to improve mortality estimates: an example with sperm whales. Meth Ecol Evol 5:27-36

Williams R, Gero S, Bejder L, Calambokidis J and others (2011) Underestimating the damage: interpreting cetacean carcass recoveries in the context of the Deepwater Horizon/BP incident. Conserv Lett 4:228-233

Submitted: May 2, 2014; Accepted: November 13, 2014

Proofs received from author(s): March 27, 2015 